Western University

Scholarship@Western

Aboriginal Policy Research Consortium International (APRCi)

2009

Security and Belonging: Reconceptualising Aboriginal Spatial Mobilities in Yamatji Country, Western Australia

Sarah Prout

Australian National University

Follow this and additional works at: https://ir.lib.uwo.ca/aprci

Part of the Other Sociology Commons

Citation of this paper:

Prout, Sarah, "Security and Belonging: Reconceptualising Aboriginal Spatial Mobilities in Yamatji Country, Western Australia" (2009). Aboriginal Policy Research Consortium International (APRCi). 337.

https://ir.lib.uwo.ca/aprci/337 
This article was downloaded by: [University of Western Ontario]

On: 30 October 2012, At: 13:22

Publisher: Routledge

Informa Ltd Registered in England and Wales Registered Number: 1072954 Registered

office: Mortimer House, 37-41 Mortimer Street, London W1T 3J H, UK

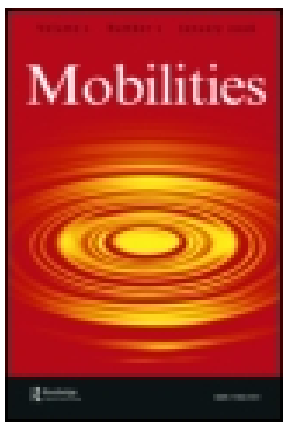

\section{Mobilities}

Publication details, including instructions for authors and subscription information:

http:// www. tandfonline.com/loi/ rmob20

\section{Security and Belonging: Reconceptualising Aboriginal Spatial Mobilities in Yamatji Country, Western Australia}

Sarah Prout ${ }^{a}$

${ }^{a}$ Centre for Aboriginal Economic Policy Research, Australian National University, Canberra, Australia Version of record first published: 02 J un 2009.

To cite this article: Sarah Prout (2009): Security and Belonging: Reconceptualising Aboriginal Spatial Mobilities in Yamatji Country, Western Australia, Mobilities, 4:2, 177-202

To link to this article: http:// dx.doi.org/ 10.1080/ 17450100902905105

\section{PLEASE SCROLL DOWN FOR ARTICLE}

Full terms and conditions of use: http://www.tandfonline.com/page/terms-andconditions

This article may be used for research, teaching, and private study purposes. Any substantial or systematic reproduction, redistribution, reselling, loan, sub-licensing, systematic supply, or distribution in any form to anyone is expressly forbidden.

The publisher does not give any warranty express or implied or make any representation that the contents will be complete or accurate or up to date. The accuracy of any instructions, formulae, and drug doses should be independently verified with primary sources. The publisher shall not be liable for any loss, actions, claims, proceedings, demand, or costs or damages whatsoever or howsoever caused arising directly or indirectly in connection with or arising out of the use of this material. 


\title{
Security and Belonging: Reconceptualising Aboriginal Spatial Mobilities in Yamatji Country, Western Australia
}

\author{
SARAH PROUT \\ Centre for Aboriginal Economic Policy Research, Australian National University, Canberra, Australia
}

\begin{abstract}
Since British colonisation of Australia began, Aboriginal mobility practices have been poorly understood within the Anglo-Australian consciousnesses. This paper examines current discourses and conceptualisations of Aboriginal mobilities in Yamatji country, Western Australia. Finding none of these explanations and interpretations singularly sufficient to encompass the diverse spatial practices of Aboriginal people in the region, the paper proposes an alternative framework for interpreting and understanding these population dynamics. The central tenet of this reconceptualisation is that contemporary Aboriginal spatialities - including spatial distribution, movements, and immobility - are iteratively shaped by the processes of procuring, contesting, and cultivating security and belonging. In a conscious shift away from generalised and pejorative interpretations of Aboriginal mobility, this more holistic framework considers historical and geographical context, cultural identity, and individual aspirations.
\end{abstract}

KEY WORDS: Aboriginal, short-term mobility, circulation, transiency, discourse, authenticity, narratives, kinship, historical policy

\section{Introduction}

Throughout colonial history, the Anglo-Australian consciousness has produced and reproduced various visions of the continents' first peoples as 'wandering nomads'; a people naturally oriented towards constant movement; a 'walkabout race'. These 'myths' and visions have generally been characterised as antithetical to those of the mainstream society and have reduced complex and dynamic Aboriginal spatialities including population distribution, movement, and immobility - to a simplistic, yet elusive, phenomenon, subject to the policy intervention of prevailing political ideology. This mythical erasure of complexity, rationality and dynamism is heavily implicated

Correspondence Address: Sarah Prout, Centre for Aboriginal Economic Policy Research, Hanna Neumann Building no. 21, Australian National University, Canberra, ACT, Australia 0200. Email: sarah.prout@ anu.edu.au 
in past Aboriginal policy failure and in contemporary spatial struggles for co-existence between Aboriginal and non-Aboriginal Australians.

From first contact, a combination of Eurocentric assumptions about normal and appropriate spatial practices, and ill-conceived interpretations of Aboriginal huntergatherer lifestyles, began to powerfully shape the colonial narrative. The nomadic nature of the Aboriginal population and their lack of visible signs of land ownership formed the rationale for the British declaration of terra nullius, and subsequent colonial settlement (Young \& Doohan, 1989). As Aboriginal mobility practices increasingly collided with the settler ideologies of expansion and settlement, the new colonial governments developed 'protectionist policies' that would attempt to contain and control Aboriginal spatiality (Hamilton 1987; Gray, 2004; Milnes, 2005). The policy eras that followed have oscillated, almost confusingly, between attempting to orchestrate, facilitate, and support Aboriginal population urbanisation (Gale, 1967; Smith, 1980) and re-distribution to remote homelands (House of Representatives Standing Committee on Aboriginal Affairs, 1987). There has, however, been a consistent emphasis, at least discursively, on reforming and remaking Aboriginal spatialities to more closely reflect the mainstream ideals of settlement and economic productivity. The result for many Aboriginal people has been generations of physical dislocation and alienation from country and kin, as well as an acute marginalisation from many mainstream social and economic institutions (Prout, 2007).

In the contemporary context, mainstream service delivery practices continue to marginalise many Aboriginal Australians because they perpetuate a spatial order that privileges sedentarism. Housing, health, and education services, for example, are primarily delivered through fixed and permanent infrastructure such as hospital clinics and schools. These service delivery practices have been developed to cater to relatively settled existences, with enough flexibility to absorb occasional, predictable employment- or lifestyle-related migrations. Consequently, Aboriginal people who continue to engage in frequent mobilities often have more sporadic and contested interactions with mainstream social service agencies. This spatial disciplining both reflects and reinforces government policies that continually fail to actively engage with or understand the contexts and alternate rationalities that shape many Aboriginal spatial practices. It also perpetuates discourses of Aboriginal mobility that focus predominantly on the ways in which Aboriginal spatial practices disrupt service delivery practices.

Not surprisingly, the mythology of 'walkabout' persists. It is often cited to pejoratively and knowingly explain away all kinds of complex spatial interactions (Fink, 1960; Hamilton, 1987; Peterson, 2004) and, to some degree, to reinforce conceptualisations of Aboriginal mobilities as somehow mysterious, even subversive. However, this simplistic notion of 'walkabout' as an innately Aboriginal characteristic is problematic for at least two reasons. Firstly, Aboriginal populations have not lived in a cultural vacuum for the past 200 years. Any contemporary mobilities they engage in cannot therefore be satisfactorily explained away as the result of a nomadic predisposition to 'wander'. Secondly, positioning frequent mobility as a marker of Indigineity implies that Aboriginal people who live relatively sedentary or 'settled' existences are somehow less authentically Aboriginal.

A superficial and fragmented comprehension of Aboriginal mobility practices is perpetuated by a lack of research that challenges dominant discourses and assumptions 
about 'normalised' spatial practices, and seeks to understand and interpret contemporary Aboriginal spatiality more holistically (Taylor \& Bell, 2004c). Research and literature concerning Aboriginal mobility has often been a by-product of some other, usually anthropological, study (see for example Fink, 1960; Tonkinson \& Tonkinson, 1979; Palmer, 1982; Altman, 1987; Birdsall, 1988; Finlayson, 1991; Cowlishaw, 1999; Moisseeff, 1999; Musharbash, 2000, 2003; Smith, 2000; Thompson, 2001), and is consequently cobbled together in a piecemeal fashion (Taylor \& Bell, 2004c, p. 1). This paucity of rigorous and focused research allows pejorative and assailable public discourses of Aboriginal mobility to circulate unchallenged with the national consciousness. It also leads to silence, rather than critical analyses, regarding service delivery practices that marginalise Aboriginal people whose mobility practices fall outside of those constructed as normal and reasonable within the dominant public discourse and policy frameworks.

A small but growing literature in post-colonial settler states such as Australia, Canada, America, and New Zealand almost universally acknowledges the need, in policy and research contexts, for more detailed understandings and robust conceptualisations of indigenous spatialities (Australia: Hamilton, 1987; Young \& Doohan, 1989; Young, 1990; Martin \& Taylor, 1996; Taylor, 1996; Warchivker et al., 2000; Peterson, 2004; Taylor \& Bell, 2004b; Memmott et al., 2006; America: Eschbach, 2004; Snipp, 2004; Canada: Frideres et al., 2004; Cooke \& Belanger, 2006; Norris \& Clatworthy, 2007; New Zealand: Barcham, 2004; Nikora et al., 2004). There are, however, a number of conceptual and methodological complexities that frustrate and constrain research efforts regarding Aboriginal mobility. Significant amongst these is the widely accepted reasoning that Aboriginal populations exhibit demographic and spatial characteristics which cannot be satisfactorily explained within the parameters of traditional migration models (Young \& Doohan 1989; Young 1990; Taylor \& Bell $1996,2004 b)$. These models, used to conceptualise and predict population movements, are inappropriate in Aboriginal contexts for at least three reasons.

Firstly, they often favour economic rationality as the chief predictor of movement. As Taylor and Bell (2004a, p. 263) have suggested, the inherent assumptions within classic economic-based migration models where movers are positioned as income maximisers', is inappropriate in the context of Aboriginal populations. Many Aboriginal people, for example, privilege responsibilities to family and ancestral 'country' above employment opportunities. These preferences are reflected in their spatial practices (Young, 1990). Secondly, traditional migration models exclude circulation (i.e., forms of movement that do not involve a permanent change in residence) or relegate it to a transitional status. Yet these circular patterns of movement are often the most common forms of movement in which Aboriginal people engage (Prout, 2007). Finally, as Chapman (1991) cautioned in the context of academic inquiry into Pacific Islander mobility processes, the fervent quest to neatly model, predict and enumerate mobility patterns, can mask the complexity, overlap, and fluidity of these processes. In essence, adherence to 'dichotomized thinking and dualistic models' can be potentially counter-productive to the over-arching agenda of developing a greater understanding of mobility processes (Chapman, 1991, p. 287).

Chapman's critique serves as a cautionary tale for academic inquiry focussing on any form of indigenous population mobility. It advocates the problematisation of dominant interpretative frameworks and the adoption of conceptualisations of Aboriginal 
mobility which embrace overlap, fluidity, and complexity. Chapman is not alone in his concerns. Wilson and Peters (2005, p. 396), in their study of First Nations migration in Canada, privileged the perspectives of migrants as part of an interrogation of the dominant interpretive frameworks and assumed categories upon which migration models are based. In Australia, Young and Doohan (1989) and Memmott et al. (2006) also adopted conceptual frameworks in their respective studies of Aboriginal mobility which allowed them to depart from conventional constructions of mobility and migration. They employed methodologies which focussed on Aboriginal narratives and definitions of their mobilities.

In recognising the weighty imperatives to develop and consolidate scholarly research and literature regarding Aboriginal mobility, Taylor and Bell propose a future direction for indigenous mobility studies:

We would argue that a primary focus should be given to further elaborating the way in which mobility dynamics and settlement outcomes are shaped by the changing interface between Indigenous culture and the encapsulating state. An enhanced understanding of these interactions, in diverse settings and at varying temporal and spatial scales is fundamental to articulation of a robust and comprehensive theory of mobility amongst Indigenous peoples ... Equally important, and perhaps more tractable, is the task of capturing the many forms of spatial activity that characterize Indigenous life ... The challenge for research is not simply to capture dynamics of these diverse forms of movement, but to understand how they intersect and interweave to underpin the lives of Indigenous peoples. (Taylor \& Bell, 2004a, pp. 265-266)

Here, Taylor and Bell identify two aspects of mobility studies that remain largely undeveloped conceptually. First, they advocate an emphasis on the changing relationship between mobility practices and Aboriginal interactions with institutional structures. Second, they articulate the need for a greater appreciation of diverse Aboriginal spatial practices and the complex interplays between them. The focus they call for is less concerned with the examination of a particular type of mobility process and more concerned with developing an understanding of the underlying circumstances, settings, and situations which give rise to the multiplicity of Aboriginal mobility processes that exist in contemporary Australia.

In responding to Taylor and Bell's proposed research agenda, this empirically oriented paper, based on $\mathrm{PhD}$ field research, seeks to understand, and indeed interpret, the complex machinations of Aboriginal mobility processes in Yamatji country, Western Australia. It approaches the task by adopting a similar conceptual orientation to that of Chapman (1991) and Wilson and Peters (2005), who favoured lived experience over migration models as an entry point to the study of population mobility. The case-study analysis begins with an overview of the research design, including the selection and characteristics of the study location, and the methodological approach adopted. The analysis then focuses on the conceptualisations and interpretive frameworks which arise from public discourse - particularly in relation to the delivery of basic government services such as health, housing, and education - in Yamatji country. It critically examines the dominant understandings, interpretations, and assumptions about Aboriginal mobility processes in the discourses, cultures, and practices of 
locally and regionally based Aboriginal and non-Aboriginal residents and public servants. In so doing, it challenges the dominant frameworks through which Aboriginal spatial practices have been and are interpreted, finding none of these explanations singularly sufficient to capture the complexity and diversity of contemporary Aboriginal spatialities in Yamatji country. The paper therefore progresses to propose a reconceptualisation of Aboriginal spatialities in Yamatji country - an alternative framework through which these spatial practices might be interpreted.

\section{Study Background}

Placing spatial parameters around a mobility study is a somewhat complex and paradoxical task. Delineating a specific geographical region within which to examine Aboriginal mobility processes is problematic because it potentially excludes from the study any mobilities that transcend these demarcations. It also raises intractable questions about the subjective nature of conceptualising geographical scale and creating boundaries. And yet, Aboriginal mobility processes are influenced and shaped by a range of broader political, cultural, administrative, social, and economic structures with which localised population studies must engage. Ignoring this broader 'regional' context undermines the analysis.

This study focuses primarily on the town of Meekatharra, Western Australia, and the mobilities that flow into, out of, and around it. There is no single definitive geographical region within which Aboriginal people living in Meekatharra undertake their mobilities. Their movements diffuse within and beyond several administrative boundaries. In recognising, however, that these mobility processes are fundamentally informed by broader structures and processes, the analysis is firmly situated within (though not constrained by) a broader regional context.

The now defunct Aboriginal and Torres Strait Islander Commission (ATSIC) included Meekatharra within the 'Yamatji' administrative region (see Figure 1). According to Berndt (1979, p. 7), the word 'Yamatji', which simply means 'man' in the local Wadjari language, emerged from a loss of separate social identities amongst particular tribes in Western Australia's mid-west. It is now used as a general collective reference to all Aboriginal people from the region and who are of 'mixed tribal origin', and to contrast them with those whose origins lie elsewhere (see also Fink, $1960,1965)$. Therefore, the notion of 'Yamatji country', as adopted in this study, is not necessarily neatly representative of specific local Indigenous custodianship or occupation but rather reflects the resilient, adaptive, and changing identities of Aboriginal people within the region.

Spatially, Yamatji country covers some $415,330.5 \mathrm{~km}^{2}$ of Western Australia, with a total population of 54,689 (Australian Bureau of Statistics, 2007a). The majority of the region's growing population live along the western coastal strip, which is dotted with increasingly popular tourism and sea-changer destinations. The region's largest centre, Geraldton, is also located on this coastal strip. The 2006 census $^{1}$ estimated that this growing port city and regional administrative centre had a population in excess of 27,000, and of these, 2314 (11.7\%) identified ${ }^{2}$ as Indigenous (Australian Bureau of Statistics, 2007b). Geraldton is a common reference point for Aboriginal people throughout Yamatji country because of the more extensive range of public and retail services available there. 


\section{WESTERN AUSTRALIA}

Case Study Region
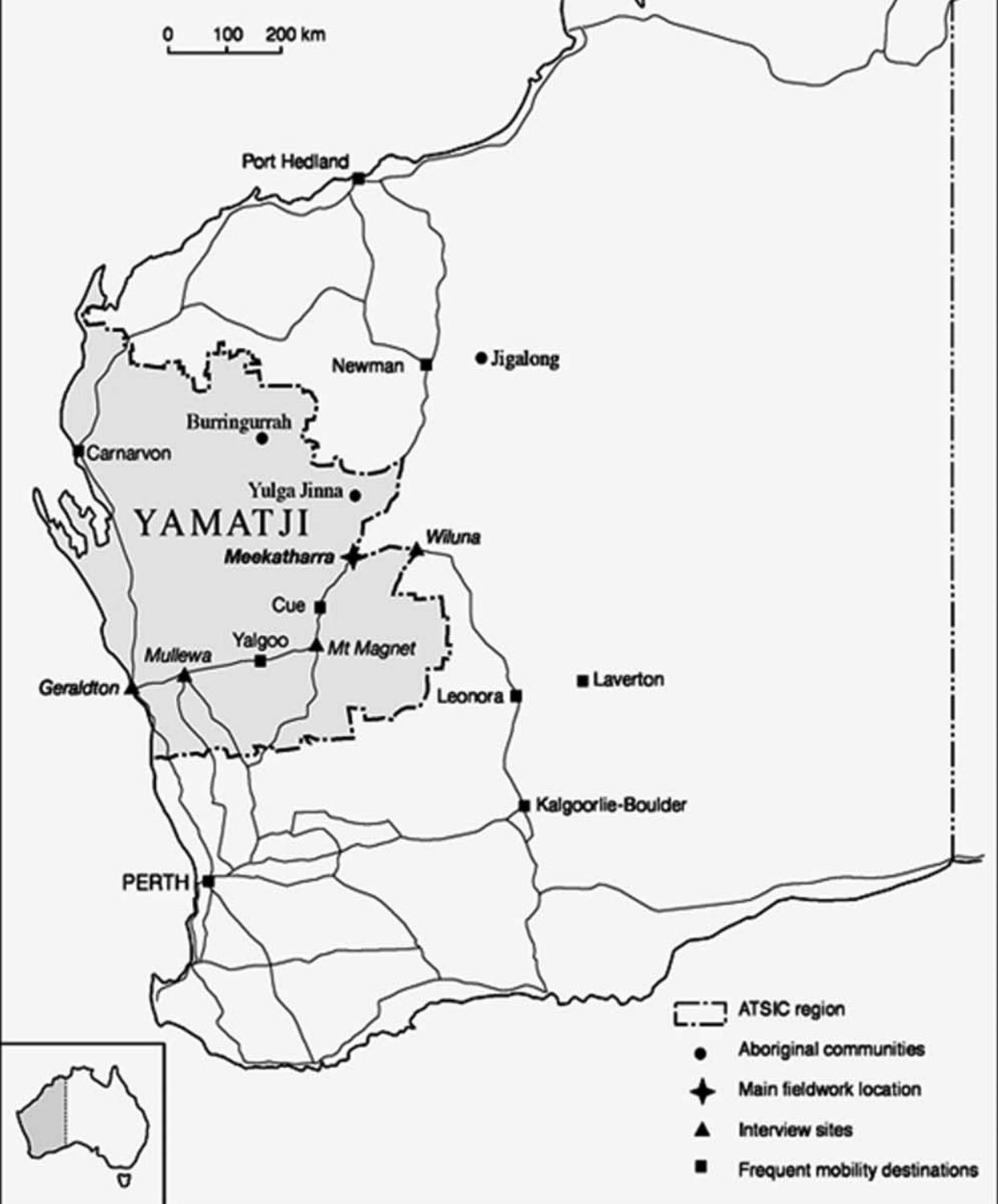

Figure 1. Yamatji country, Western Australia. Source: Modified from Prout (2007, p. 4). 
Moving inland, the country becomes increasingly arid and the primary industries are pastoralism and mining. The landscape is characterised by rocky outcrops and hardy scrublands. It is dotted with windmills and mining pits, and coloured in shades of earthy reds, greens, and greys. In the summer months, it is suffocatingly hot and dry. However, when the rains come and spring arrives, creek beds fill and wildflowers and grasses emerge to produce a stunning display of colour and life. This inland part of the region is abundant in kangaroo, bungarras (giant goannas), and wedge-tailed eagles. Feral goats and donkeys, cattle, and sheep also roam the country.

In this more 'remote' portion of the region, population density is low. There are only a handful of townships east of Geraldton. Of these, Meekatharra is the largest with an estimated population in 2006 of 799 (Australian Bureau of Statistics, 2007c). Many of the region's rural towns are experiencing severe decline as a result of fluctuating commodity prices, the increasing withdrawal of economic benefits from local mining ventures, a downturn in the pastoral industry, and neo-liberal governance dictating service withdrawal from rural areas. These conditions are changing the demographic structure of the more remote portions of the region. As greater numbers of non-Aboriginal people abandon their unviable rural livelihoods, these inland areas are becoming increasingly 'Aboriginal' domains. Although more than half of the region's Aboriginal population are located in the major coastal towns of Carnarvon and Geraldton, and in total comprise only $10 \%$ of the regional population, the Aboriginal population makes up a far greater percentage of the total population in the inland portions of the region. In Meekatharra for example, the identifying Indigenous population comprises $44 \%$ of the total population (Australian Bureau of Statistics, 2007c).

The Aboriginal population currently living in Yamatji country are culturally and socially diverse. In the late 1950 s, Fink - the only social researcher to have undertaken significant, documented ethnographic research in Yamatji country (albeit confined to the southern part of the region known as the Murchison) - described a 'cultural loss' amongst Aboriginal population in her fieldwork area:

One can study among them the transition from being culturally Aborigines to becoming merely a group who are descended from Aborigines and who are still differentially treated from the rest of the white community because of this fact. (Fink, 1960, p. 30)

Similarly, in setting the context of his 1957 study of Aboriginal mobility practices in western New South Wales (NSW), Beckett (1965, p. 7) described the Aboriginal population in his study region as having essentially lost their culture. He based his assertion on four observations: firstly, that tribal groupings were dispersed and local populations were of mixed origin; secondly, that there had been no initiation ceremonies in the region for more than 50 years; thirdly, that old kinship behaviours (including prescribed marriages) had been forgotten; and fourthly, that tribal languages were scarcely spoken.

Beckett and Fink's assumption that the absence of these cultural expressions was indicative of wholesale cultural breakdown is highly contestable. For example, although a number of research participants in the present study contrasted themselves specifically, or Yamatji people more generally, with the more 'tribal' or 'traditional' people of the Western Desert, most of these participants did not have a diminished 
sense of their own Aboriginal identity. The distinction appeared to be one of cultural difference rather than loss. Nevertheless, Beckett's observations provide a useful framework for discussing some of the social and cultural characteristics of the Aboriginal population living in Yamatji country today.

In relation to origins and ancestry, Aboriginal people living in Yamatji country have diverse backgrounds:

Again, you're not necessarily dealing with all Yamatji people either. We've got one of the most - you talk about multiculturalism; blackfellas are more multicultural than white people. They are! Half of them have got different - there's no specific one - blackfellas aren't blackfellas in the sense of blackfella/ whitefella. They've got German, French, Irish, Pom, ${ }^{3}$ you name it! Afghan, the whole box and dice ... roaming around, you've got mother's Noongar, but the father's Yamatji. I'm in the same situation: black mother, white father. My Grandfather is an Afghan. My Grandmother, part Irish. So you've got all these mixed people here. (Interviewee A)

In relation to kinship structures in the region, Fink (1960) suggested that pre-colonial forms of social organisation and marriage arrangements no longer exist. However, fieldwork for the present study indicated that whilst pre-colonial structures may no longer be in place, Aboriginal people in Yamatji country maintain a detailed knowledge of their kin relationships. These relationships remain integral to social organisation and provide a framework for determining what partnerships are and are not appropriate.

Finally, in relation to language, few Aboriginal dialects are spoken in Yamatji country today. Gerritsen (1994, p. 103) suggested that prior to colonisation, there were 18 distinct Aboriginal language groups within the region. In more recent times though, traditional languages are spoken in a generalised form - modern Wadjari being one example. In 1973, Douglas (1981) estimated that there were probably fewer than 200 Wadjari speakers remaining in the region, and these individuals were scattered throughout the region from Meekatharra to Geraldton. According to the 2006 census, 91\% of Aboriginal respondents in Yamatji country indicated that they spoke only English. Only 2\% of Aboriginal respondents (99 people) indicated that they spoke an Aboriginal or Torres Strait Islander language.

\section{The Methodological Approach}

Since the primary objective of the research was to explore local perceptions and experiences of Aboriginal spatial mobility in Meekatharra specifically, and Yamatji country more generally, 52 semi-structured and in-depth interviews were conducted with Aboriginal and non-Aboriginal research participants from a wide range of cultural and professional backgrounds and in various locations throughout the region. Most participants fell into one of four general categories of classification.

1. Locally based non-Aboriginal service providers and local government representatives including shire employees, representatives of State Government health, housing education and community development agencies, and other non-government service providers. 
2. Local Aboriginal residents, including locally based Aboriginal service providers.

3. Regionally based service providers.

4. Local business operators.

Table 1 provides a more detailed breakdown of research participants by Indigenous status, gender, and location.

The representativeness of participants by Indigenous status reflects the study's emphasis on the perspectives and experiences of both Aboriginal and non-Aboriginal people with regard to Aboriginal mobility processes. It also reflects intentional sampling according to the four categories listed above. The clear bias toward the perspectives of Aboriginal women reflects a conscious choice of protocol during the fieldwork process. Early informal conversations with local Aboriginal residents about the research indicated that interviewing Aboriginal men by themselves could easily be construed as inappropriate. Undoubtedly, the gendered nature of the sample has influenced the nature of the data. However, the fieldwork process supported Kenny et al.'s (2004, p. 20) experience, who observed in their research that the stories of Canadian aboriginal women were broader than just individual experience because they included in their own stories the lives of children and men. Many women who were interviewed in Meekatharra described parts of their husbands, partners and/or father's stories in conveying their own journeys.

The location and role of research participants was also a significant component of the research design and focus. The input of locally based Aboriginal participants was central to the study. Their 'spatial stories' of travelling and 'settling' brought a rich and grounded context to the research narrative. In addition, many Aboriginal participants were also service providers. These dually positioned interviews produced unique and invaluable insights into the broader processes and specific circumstances shaping Aboriginal spatiality.

Regionally based service providers spoke to the broader context regarding service provision and Aboriginal mobility in Yamatji country. It was within this context that the localised narratives from Meekatharra and other fieldwork towns could be situated. The input of locally based service providers was significant to the research because they represent the institutions of social and political control within their communities and their work involves interactions with a broad cross-section of the local and regional community - both transient and sedentary. Although the majority of these locally based interviews took place in Meekatharra, four additional comparative

Table 1. Select characteristics of research participants

\begin{tabular}{lccr}
\hline & Aboriginal & Non-Aboriginal & Totals \\
\hline Female / local (Meekatharra) & 15 & 9 & 24 \\
Female / local (other town) & - & 1 & 1 \\
Female / regional (Geraldton) & 3 & 2 & 5 \\
Male / local (Meekatharra) & - & 13 & 13 \\
Male / local (other town) & 1 & 3 & 4 \\
Male / regional (Geraldton) & 3 & 2 & 5 \\
Total & 22 & 30 & $\mathbf{5 2}$ \\
\hline
\end{tabular}


interviews were conducted with health and education providers in Mullewa, Mt Magnet and Wiluna (see Figure 1). These interviews were not intended to provide a detailed or representative analysis of Aboriginal mobility processes in each town, but rather to ground regionally based interviews by highlighting similarities and differences in comparative localised contexts.

Employing different interview formats amongst this diverse group of research participants produced a rich and complex, variously scaled and nuanced account of Aboriginal mobilities in Yamatji country. An active and prolonged presence in the field also served the important tasks of triangulation: it provided a means through which interview data could be contextualised, supplemented, and cross-checked.

\section{Contemporary Discourses of Aboriginal Mobilities}

Contemporary Aboriginal mobility practices in Yamatji country are 'read through' the public consciousness in a variety of ways. However, two perspectives or discourses dominated. The first discourse categorised contemporary Aboriginal spatial practices in the region as characteristic of either a 'core' or 'transient' population (Prout, 2007). According to this discourse, the 'core' are the more settled, or permanently residing population. In Meekatharra for example, the 'core' comprises members of several family groups who are securely woven into the socioeconomic fabric of the town through mechanisms such as mainstream employment, homeownership and/or familial leadership roles in older age. The 'transients' by contrast, who are often younger family members of the 'core', engage in frequent movements largely within geographically contained regions and sometimes along expansive beats to extended family in more remote locations. Many interviewees, particularly nonAboriginal service providers, described these mobilities as spontaneous, noting an absence of planning and preparation. They also described such movements as being temporally variable - they could be anywhere in length, from one week to several years. Most short-term mobilities are circular in nature, with frequent journeys away from a 'home-base' and continual returns to it; a process defined by Bedford (1981) and Chapman and Prothero (1985) in the Melanesian context as 'circulation'. Other mobilities involve more linear movements between a series of places, usually locations of family members, in what Young (1990) has referred to as 'chain migrations'.

A number of research participants attached neither a positive nor negative value to the spatial practices of those in either category, identifying them simply to clarify that not all Aboriginal people are highly mobile. For others, the discourse of a 'core' and 'transient' population seemed to simultaneously reflect and reinforce their positioning of each group within the town's social fabric: the concept of a core, conjuring notions of centrality, significance, and strength, while the 'transients' are relegated to a peripheral status; outside of normalised spatial practices and for one reason or another, on the margins of mainstream society. Here, the 'core' were considered more 'settled' and 'integrated' into the community. They were perceived as the more responsible, reliable, and stable members of the Aboriginal community and were described as respected by both Aboriginal and non-Aboriginal people. In contrast, frequent mobility through Meekatharra, and Yamatji country more generally, was often deemed 'non-traditional' and associated with anti-social behaviours, irresponsibility, laziness, and free-loading. 
These perspectives relate closely to the second discourse that circulated locally as a lens through which Aboriginal mobility practices were interpreted. According to this discourse, the legitimacy of Aboriginal mobilities was evaluated based upon particular constructions of 'authentic' Aboriginality. Aboriginal spatial practices which closely mirrored those of the non-Aboriginal population (i.e., either sedentarisation or long-term migrations for non-contingent reasons such as employment and education opportunities) were often perceived as an indication of a person's assimilation into mainstream non-Aboriginal society. In general, these types of spatial practices were discussed less frequently in interviews, particularly by non-Aboriginal service providers. There are two possible explanations for this. Interviewees may have understood these kinds of spatial practices as 'normal' and therefore of little relevance to their understanding of the research agenda. Alternatively they may not have considered such movements authentically 'Aboriginal,' thus assuming they were outside of the mandate of interview discussions.

Interpretations of sedentary lifestyles as 'assimilated' position authentic Aboriginal spatiality as oppositional to the notion of settlement. Essentially, they present 'settled spaces' as non-Aboriginal domains. According to this authenticity discourse, frequent mobilities are viewed as more genuinely 'Aboriginal' forms of spatial practices, but only those which characteristically conform to the interpreters' expectations of what is legitimately 'Aboriginal'. For some interviewees, all short-term circular mobilities, regardless of their rationale or form, were considered genuinely Aboriginal - a product of a nomadic pre-disposition and an expression of their cultural identity. For others, only those mobilities which were undertaken for 'traditional' reasons (presumably referring to hunting, ceremonial attendance and seasonal migrations) or by 'traditional' people were deemed to be authentic. Many people in the fieldwork region who hold this latter view suggested that few of the movements amongst Aboriginal people in Yamatji country could be considered authentically 'Aboriginal'.

Underneath these overarching discourses of core/transient, and authentic Aboriginal spatiality, explanations and interpretations of Aboriginal mobility in Yamatji country were diverse and sometimes contradictory. A range of variously articulated and variously influential voices told different stories which either reinforced or challenged the authenticity discourse.

\section{A Nomadic Pre-disposition}

Although some interviewees felt that Aboriginal mobilities in the fieldwork region were not 'traditional', many research participants still explained frequent mobilities as being the product of a nomadic pre-disposition. As the following interview excerpt illustrates, the language of nomadism or wandering was used by several interviewees to explain the spatial practice of the more transient Aboriginal population in Yamatji country:

Like they only come through for a few month or two months, sometimes even less, and they go again. They don't, stick around for very long. They come and they interrupt all the other families and eat all their food and everything and just wander off like nomads. (Interviewee B) 
Without invoking the same host of associated negative connotations, a number of Aboriginal interviewees also discussed the influence of a nomadic tradition on the contemporary spatial practices of highly mobile Aboriginal people, sometimes referring to 'blackfella' or 'travelling' blood.

\section{Reflection of Values and Priorities}

Another common explanation of frequent Aboriginal mobilities in Yamatji country was that such lifestyles could be understood as a reflection of priorities or values. For example, many interviewees suggested that family was a chief priority for most Aboriginal people, transcending other commitments and circumstances. Consequently, the willingness to 'drop everything' to attend a funeral or visit a sick family member, or to simply call in on their kin was in many cases more important than owning their own home or having stable employment.

Interviewee: I think family ties are still fairly strong. And responsibility to family is still very strong as well. And there have been occasions where people have moved away but they have gone back for whatever reason. Might have stayed there a month, two months then they come back home so-to-speak. Back to Gero, Carnarvon, wherever. Couple of weeks and they're off again.

Interviewer: So, it's those family ties that kind of cause transiency?

Interviewee: Yeh, I think so. I mean, that's my understanding of it all [pause]. Obligation to family. [pause] I can't think of any other reason other than family. (Interviewee A)

Some interviewees admired the lifestyles of the transient population, especially where they believed this group gave priority to family and adventure above accumulating personal wealth and material possessions. Others framed the same discussion in the more negative way, suggesting that highly transient Aboriginal people did not value a work ethic, or their health, or their children's education. They regard mobility as perhaps indicative of laziness and irresponsibility.

\section{No 'Ties'}

Following on from this notion of reflected values and priorities, a number of interviewees suggested that because some Aboriginal people did not value things that would anchor them to a particular place, a transient lifestyle was more easily facilitated:

The other thing is that a lot of these people probably don't (and I say these people, I'm talking about our people, my people) don't actually (how's a good way of putting it?) don't value what we would call assets and things like that. So therefore, they don't aspire to buying their own home. There are lots of people who are caught up in a cycle of alcohol and substance misuse, and therefore have a tendency to just go with the flow. And if people are going to the next town, the likelihood is that they'll go with their friends that they drink with. And I suppose if you actually don't have assets that you have to look after then you 
don't have a worry in the world. You know, you just swhippp [sound indicating rapid exit], off you go basically. (Interviewee C)

Not having mainstream employment, children of school age, an abundance of material possessions or fixed assets such as property to maintain (either through rental or ownership), were common observations to which both Aboriginal and non-Aboriginal participants attributed the capacity of highly mobile Aboriginal people to engage in such lifestyles:

The lack of employment obviously makes it more possible for people to be more transient. So if someone's unemployed and they've got no kids, they can virtually appear anywhere the following day because they're at a loose end. And home is where you hang your hat rather than anywhere specific. (Interviewee D)

In interviews, a person's place in the lifecycle was often linked to a notion of spatial anchors. For example, dependent children were considered a tie which often bound parent(s) to a particular place through the pressure or desire to remain consistently near one school or health service. Those without children were therefore often perceived to have more spatial freedom.

\section{Trouble}

Another common explanation of the transient Aboriginal population in Meekatharra and the fieldwork region more generally was that their movements were motivated by trouble or conflict of some kind. Family feuds, escaping the law (both traditional and mainstream), and outstaying one's welcome were common examples associating transiency with 'turbulent lifestyles'. In Meekatharra, as in the nearby town of Mt Magnet (see Figure 1), it was most often transient people who were considered to be responsible for the vast majority of criminal activity taking place in those towns. Some interviewees even suggested that Meekatharra attracted trouble because of its reputation as a lawless town. According to this perspective, Meekatharra provided a refuge for individuals who led troubled lives as neither the mainstream police service nor traditional Aboriginal Law were considered particularly active in the town. Consequently, individuals travel to Meekatharra to seek refuge from either 'whitefella' or 'blackfella' law and/or punishment, or to feel at ease to create trouble in the town without fear of consequences.

The often public nature of 'troubled mobilities' is such that highly mobile Aboriginal people are commonly viewed by Aboriginal and non-Aboriginal people as being motivated primarily by some sort of troubled existence. Their inability to settle in one place can be perceived as a product of refusal to take responsibility for personal problems by continually creating trouble and then running from it: a cycle of conflict. One interviewee believed that perhaps these conflicts actually formed part of a greater chaotic existence which was deliberately cultivated in order to counter a potentially bored existence:

Their lives are rather chaotic really compared to the lives of, well, if I take myself. I've got an extremely settled life compared to most of the Aboriginal 
people I know. Even people who live settled lives with jobs and all that, they even, they always talk about going somewhere else. After a little while they want to move on. Even if they don't do it. It seems to be something that, they get bored. I think Aboriginal people they love excitement. We all love excitement I suppose [laughs] but they seem to crave, they seem to really go for it and be really motivated to, or maybe a boring existence is maybe something that they suffer from more. Maybe it's wrong. Maybe it's just my European view on it all. But that's what it looks like anyway - that they can't stand boredom and things being the same. Things have to move. Things have to - the social and physical environment has to change every now and then ... part of it is because their life in the town, where they live somewhere is very chaotic with illnesses, with people moving in, people moving out, break-ins, people going to jail, fights, all the - forever stories about how their lives are being screwed up [pause] by things that happen and towards things that happen to them all the time. (Interviewee E)

For some interviewees, 'troubled mobilities' reinforced negative perceptions of more itinerant individuals. However, a select few research participants positioned this 'turbulence' primarily as the product of socioeconomic status rather than ethnicity. Similarities were drawn with non-Aboriginal people of low-socioeconomic status who lead similarly troubled and transient existences because of their peripheral status within mainstream society.

\section{Socialisation}

The concept of socialisation was also an explanatory theme in several interviews. A number of service providers, both Aboriginal and non-Aboriginal, suggested that, like most people, Aboriginal people were generally a product of their experiences. According to this perspective, those raised in an environment of frequent spatial mobility - whether such movements fulfilled important social or cultural obligations, or because of a troubled existence - would internalise and reproduce these practices. For example, Aboriginal parents who remained permanent residents in a particular place and travelled only during school or work holidays, instilled similar values in their children. Many interviewees who now form part of the 'core' describe being raised by parents who placed great value on their own employment and their children's education.

This concept of socialisation was also used by a number of interviewees to explain the regionally contained mobilities of many transient individuals: a person will tend to travel within the region because it's what they know. If their parents travelled and worked within the region, they are likely to follow a similar pattern. If their parents travelled and worked outside of the region, they are more likely to develop ties outside of the region and feel more comfortable following that pattern. Socialisation was also used to explain spontaneity in short-term mobilities. According to this perspective, children learn patterns from their parents about either living 'day to day' and consequently engaging in opportunistic mobilities, or living according to a set of less flexible and predetermined goals and plans. 


\section{Accessing Services}

Finally, interviewees described engagement with mainstream government services such as health, housing, and education - as a factor that significantly influenced Aboriginal spatial practices (see Prout, 2008). A number of services providers described the ways in which frequent Aboriginal mobility throughout the region militates against the effective delivery of health services by engendering service discontinuity and resource wastage. Similarly, many interviewees, even those that were not involved in delivering education services, expressed concern about the detrimental effects of Aboriginal mobility on schools and the academic progress of students. Indeed the effectual relationship between Aboriginal transience and mainstream education was one of the most contentious points of public discourse in the fieldwork region:

Interviewee: And that's one of the hardest things at school because the kids are just - it's just a complete lack of education for the kids that are just carted around and never face the school because they haven't any permanent place of residency. And that's a big issue all over.

Interviewer: So kids coming into school for short periods and then -

Interviewee: Coming into town for short periods, and not even attending school. And we see a lot of that; kids that come and don't attend. They - Aboriginal people tend to shift around a lot for funerals and things and a lot of times their kids just miss schooling completely. And it's got to have an impact on the kid in its later life.

Interviewer: The gaps in schooling, or going to different schools?

Interviewee: The gaps in schooling and going to different schools. You set up a program and if you're going to start the program, you want the kid here from the start to the finish if you want to teach them something. And unless you're an exceptional sort of a student, chopping and changing can't help can it. (Interviewee F)

For many interviewees, particularly non-Aboriginal service providers, the spontaneous and contingent movements amongst the Aboriginal population were constructed as problematic for service provision, particularly in terms of service continuity and resource allocation. These movements could not be predicted, monitored, or planned for. Some service providers had become disenfranchised by and disengaged from their mobile clientele and were feeling as though their work is ultimately ineffectual.

By contrast, many Aboriginal interviewees suggested that Aboriginal people are increasingly 'chasing services'. They explained that service rationalisation and resulting withdrawal from more remote areas is changing the spatial practice of many Aboriginal families:

There's quite a movement of people out of the remote areas for education. It's not only a non-Aboriginal thing. I left Meekatharra for my kids' schooling. I'll be buggered if about three of four people with kids the same age as mine 
Aboriginal community didn't turn up in Geraldton about the same time. Getting their kids to a high school where they can actually have a chance at a matriculation rather than just entertaining them for four years. (Interviewee $\mathrm{G}$ )

Some non-Aboriginal research participants also acknowledged that the way in which services are delivered, and Aboriginal engagement with them, impacts Aboriginal spatiality. In particular, they noted that service withdrawal from more remote areas was responsible for an increase in migration toward larger regional centres. Other interviewees felt that the range of services available to Aboriginal people, and the ease with which they could be accessed, empowered itinerant individuals. The availability of public housing in rural areas, the number of schools and ease of enrolment, were cited locally as conditions which combined to create an environment where Aboriginal people could take advantage of service networks whilst remaining engaged in itinerant lifestyles. For some, such statements were merely reflections and observations. For others, these observations were accompanied by attitudes of concern or derision over a perceived pandering to itinerant whims or catering to indulgent mobility practices.

Chapman and Prothero (1985) and more recently Taylor and Bell (2004c), have described the ways in which circular networks have been reconfigured from their traditional forms as Aboriginal people have incorporated 'modern' conveniences into their spheres of existence. Research participants in Yamatji country identified such practices as they described the relationship between Aboriginal spatiality and mainstream service institutions.

\section{Towards a Reconceptualisation}

Each of the contemporary interpretations and explanations of Aboriginal mobility presented above is problematic or partial. The notion of 'core' and 'transient' populations, whilst perhaps in some ways reflective of reality, establishes a siloed distinction between two types of movement, masking the range of mobilities and the permeability of such categorisations. Many Aboriginal people move fluidly between being 'core' and 'transient' at different points throughout their lives. The 'authenticity discourse' is also problematic. As well as being remarkably exclusive, it perpetuates and reinforces marginalising discourses of certain types of mobility. Aboriginal spatial practices cannot be explained simply as a matter of those who have assimilated into Aboriginal society and those who remain essentially nomadic. The data presented above allude to a complexity of processes underlying Aboriginal mobilities; a subsurface machination of motivations, restrictions, and facilitating factors. The culmination of these conditions is a discursive agitation toward the abandonment of simplistic generalisations and fragmented interpretations of Aboriginal mobility practices. There is a clear need to re-conceptualise Aboriginal spatialities in a way which make sense of the variety of spatial practices and engagements with mainstream services, without reducing them or erasing their complexity. This reconceptualisation must be a more holistic approach which is able to incorporate the complex and dynamic social, cultural, economic, and spatial practices of Aboriginal peoples.

Whist none of the explanations or interpretations presented above can singularly provide a satisfactory foundation for understanding the complex range of mobilities 
in which Aboriginal people engage, almost all of them point to a common underlying process from which a more comprehensive interpretive framework might be drawn. That is, that Aboriginal mobilities, both traditionally and contemporarily, can be understood as being based upon the procurement, contestation, and cultivation of social, cultural, and economic security and belonging. Conceptualising Aboriginal spatial practices in this way provides an alternative epistemological vantage point on the rationalities that inform the complex and fluid mobility processes enacted in Yamatji country. It also creates the reflective space to situate the many explanations of mobility that have so far been explored. Priorities, for example, can be seen as a function of where people derive their security and belonging. Fractious interactions with mainstream services, passive relationships to the mainstream economy, and 'troubled' mobilities are often the result of contestation over security and belonging.

Explanations of nomadic pre-dispositions can also be accommodated if traditional hunter-gatherer lifestyles are understood to be motivated by the maintenance and preservation of economic, social, and cultural security and belonging. Prior to European settlement of Australia, Aboriginal security and belonging were derived from relationships to kin and country. Intricate systems of caring for country had been established and upheld for generations through story and practice. Indeed, country and culture were closely enmeshed and identity was deeply embedded in this relationship (Rose, 1996). In addition, complex kinship and relatedness systems formed the basis of social organisation, and affirmed identity (Elkin, 1979). The significance of kinship and country as sources of belonging and security were expressed through movements to obtain and maintain food sources, trade, and attend ceremonies and cultural activities. All of these processes provided an economy, an identity and a social fabric woven of people and country.

Rather than interpreting contemporary mobility processes that do not conform to these traditional forms and rationales as some sort of loss and/or betrayal of traditions, as public discourse commonly does, they can be understood as ongoing processes of procuring, cultivating, and contesting security and belonging. European settlement did not render mobility processes obsolete, unnecessary, or unacceptable to many Aboriginal people. Rather, mobility remained in many ways essential to survival, albeit adapted and reconfigured as a response to colonial intervention. When placed within a geographically specific historical context, unique Aboriginal responses and adaptations to colonial circumstances become apparent, as does the need to respond to these specificities.

Hamilton (1987), for example, argued that contemporary Aboriginal mobility practices are not merely the reflection of some nomadic pre-disposition to wander, but rather the result of post-settlement adaptations and adjustments to the marginalising forces of the new colonial economic order. Following her qualitative study of Aboriginal mobility practices on a remote cattle station in northern South Australia in the early 1970s, Hamilton explained that for two reasons, sedentarised lifestyles had not been viable options for Aboriginal people in the face of the ever expanding colonial frontier. First, traditional hunter-gatherer economies had been decimated by the encroachment of European settlement, forcing most Aboriginal people either into employment of some kind or into welfare dependency. However, the nature of work available to them was seasonal, varying both temporally and spatially. Therefore, any sustained engagement with the mainstream economy required frequent movement. 
Second, access to basic services (e.g., health, housing, education), which required relative sedentarisation, was not available to Aboriginal people.

Without erasing the role of pre-settlement mobility practices in contemporary lifestyles, Hamilton (1987) suggested that this new spatial adjustment was encouraged and sustained by the fact that Aboriginal cultural and social obligations required a similar pattern of movement to those necessitated by their marginalised position within the dominating landscape of European 'progress' and 'development'. In the face of limited options for integration into the mainstream society, Hamilton (1987) argues that networks of resources, reciprocity, and responsibility amongst and between kinship groups became pivotal structures of socioeconomic survival. Aboriginal people invested significant resources into maintaining strong kinship networks which would provide them with economic security. Maintaining these networks required that they be frequently called upon, thus engendering significant mobility (Hamilton, 1987).

As in Hamilton's South Australian context, colonisation also brought significant changes to the sources from which Aboriginal people in Yamatji country were able to derive their security and belonging. As traditional hunter-gatherer economies were decimated by encroaching British settlement, new forms of economic survival became necessary (Fink, 1960, 1965). The mobility practices of Aboriginal people began to change and adapt to the new boundaries, seen and unseen, which were asserted through spatially oppressive government policies. As Hamilton explained, increasing engagement with the pastoral industry and the mainstream economy were significant in this process of re-shaping Aboriginal spatial practices.

In Yamatji country however, Hamilton's exclusive focus on economic considerations is too narrow. It fails to adequately acknowledge the central role of government policies in affecting Aboriginal spatiality. Protectionist policies and the practice of forcibly removing Aboriginal children from their families and placing them in government institutions and reserves dramatically altered the sources from which Aboriginal people were able to actively derive security and belonging. Indeed, this policy era arguably had a more profound effect on Aboriginal spatiality in Yamatji country than any subsequent government policy era. Those taken, referred to as the Stolen Generations, were alienated from their country and kin and forced into new 'artificial' communities of people with whom they may otherwise have never interacted. In addition, many of these displaced children were later sent out from the institutions which had been their homes for many years, to work on country which was not their own. They were forced to establish new spaces of belonging and security. The result was that family networks are now far more expansive than they traditionally would have been:

You see increased transiency related to funerals and that can be tracked back to what's called the Stolen Generation because as a lot of people were moved from stations and that when voting rights came in, and they ended up down on Moore River Reserve and places like that, that actually, because those people all lived together, they actually became family. So in fact, you ended up with significant numbers of displaced people who then had to take on the role of family members. So you might have had for instance at Moore River, you had Pilbara people mixing in with Murchison people who traditionally would not have 
mixed at all. They would have moved in their small cultural area. But because of that they were all moved together, then it actually expanded the areas over which it was then seen as required to attend - like if a funeral happened or something. So there's really a strong requirement on Aboriginal people to attend. So in fact, they are travelling much greater distances than what they would have traditionally. And you know, today, it's just 'Well, that's what we have to do because they're our family'. You know some of the things that have happened to them in the past have affected their ability. (Interviewee $\mathrm{H}$ )

Ironically, policies originally orchestrated to discipline and reform Aboriginal mobilities often resulted in increased movement. The geographical extent of these outstretched family networks can be considerable. Indeed, these expansive webs of connectedness are one of the primary attributes for which Aboriginal mobilities are often constructed as problematic within service provision frameworks. If Australia, or even Western Australia, was closer in size to Great Britain, for example, then the frequent movement between even the furthest possible extensions of family associations would present far fewer logistical challenges for service providers. However, as a result of the impacts of government policy, some Aboriginal people in Meekatharra now have family hundreds (and in some cases thousands) of kilometres in each direction.

A number of ethnographic studies in a range of geographical and temporal settings across Australia have all confirmed the significance of kinship networks in informing Aboriginal spatiality (Beckett, 1988; Birdsall, 1988; Young and Doohan, 1989; Smith, 2004). In each of these settings, family networks were integral to social and economic security of the Aboriginal people who engaged in them, particularly in the absence of desire or opportunity to become more integrated into the mainstream economy. Accordingly, Aboriginal people who live on the margins of the mainstream economy generally engage in spatially bounded short-term, circular, or chain migrations as a function of exercising and maintaining their familial networks of support. As in these other contexts, family is one of the key factors that shape both the temporal and spatial characteristics of Aboriginal spatiality in Yamatji country. It is a primary source of security and belonging for many Aboriginal people in the region. Networks of extended family members facilitate and command frequent, spontaneous and temporally unpredictable mobilities, particularly for those who draw upon them as a primary source of support, and economic and social security:

no I don't make sure that I've got enough to get there and back. I've got enough to start out with. But I rely on, I don't know, that everyone is gonna see me right. And I think that's the main aim of [relatives]. You know, you're gonna be right when you get there. Even if you go and - when we go and stay with [my son], I know that they're not gonna be on the bone forever. Next payday, they'll give me enough to get home again. Or they'll go and book up petrol and give me a couple of dollars for the road, and things like that. So that's my, probably my safeguard, my safety net. Go to [relatives] instead of getting there and being stranded. (Interviewee I)

As the above interview excerpt suggests, familial networks also shape the geographical limits of mobility practices of many Aboriginal people. Within them, 
there is a normalised expectation of reciprocal exchange, and beyond them there is uncertainty:

Interviewee: I think it all goes back to when there were different skin groups and tribes and this was your area, this was where you belonged, this was where you stayed. You can't override those boundaries. You can through invitation. I mean we get quite upset if people come and live in our town who actually have got no family connections. 'Why are you coming up here?' It's all about ownership. And having family connections. If you haven't got any, why the hell are you coming up here?

Interviewer: Are there a lot of people that seem to do that?

Interviewee: You get your odd ones now and again. But you find they don't stay too long because of that family connection. If they haven't got the support, and they keep on going home to visit family, they end up moving back in the long run anyway. So you might get them stay six months, 12 months, 'nah, we're out of here'. Or if say if three or four of them came up for a different change or a different lifestyle or for work, and then one goes back, well you'll find the others will follow. So I think it's all got to do with family and blood ties, is why the movement is. (Interviewee J)

Relationships within and between family structures also include and produce considerable contestation as individuals and extended family members explore and establish, distinguish, and test their social identity and cultural belonging. These contestations also prompt 'troubled mobilities'. Almost as frequently as they mentioned family as being a primary motivator of Aboriginal mobilities, interviewees described feuding and domestic violence as contributing significantly to Aboriginal itinerancy in the region. So, whilst Aboriginal mobilities are often prompted by a need and desire to cultivate and safeguard networks of support and reciprocity, they can also be a response to conflicts arising from within those networks. Indeed, many specific movements affect both modalities.

Hamilton (1987) proposed that Aboriginal people would remain dependent on familial networks as the sole sources of their economic security only as long as they remained living in remote areas, had few opportunities for integration into the mainstream economy, depended upon government welfare, and had few chances of social mobility. In Yamatji country however, the realities of contemporary Aboriginal spatiality do not reflect a simple set of trade-offs or polarities between social and spatial mobility. Certainly, those who actively engage with mainstream social and economic institutions have the potential to draw significant security from these interactions and therefore become less dependent on family as sources of security. And, in many circumstances, their spatial practices reflect this orientation: they are often more 'settled' and may engage in long-term migrations to pursue mainstream opportunities. In the reverse context, those who have a less active and more contested relationship with mainstream institutions may derive greater security from family networks. Their mobility practices may be considerably more frequent as a result of a need and desire to maintain those networks. These individuals may conform to what one interviewee 
referred to as a 'welfare culture'. And undoubtedly, they are less spatially constrained than those whose employment 'anchors' them to a particular locale.

However, these two scenarios do not represent a bipolar choice - two alternative models of Aboriginal mobility in Yamatji country - where individuals derive their security and belonging from either mainstream institutions or familial structures. The majority of Aboriginal people in the region derive their security and belonging, and thus express their spatiality, from a complex interplay between the two. This interplay is mediated by: (a) the corollaries of colonial policies that sought to fracture Aboriginal connections to kin and country and reform their nomadic tendencies; (b) responses to contemporary government policy and practice; (c) individual life-stage, circumstances, and aspirations; and (d) socio-cultural identity, obligations, and expressions.

The reconfiguration of both relationships to country and kin which many Yamatji people experienced through colonising policies fostered economic dependence on kinship networks. It also increased the significance of family networks as spaces where identity and belonging are variously affirmed and rooted. Thus, mobility practices which engage networks of support and reciprocity might not only be conceived as exercises central to economic survival, but additionally or alternatively as cultural practices which foster identity and belonging. Family structures have adapted and persisted as spaces of social and cultural resiliency and sovereignty. Today, family remains an important source of belonging and cultural identity for most Aboriginal people in Yamatji country, regardless of their employment status or degree of engagement with mainstream services. Whether they serve as a source of economic and social security, an indicator of status and standing, or a cultural beacon, family networks are deeply intertwined in the processes of procuring, contesting, and cultivating security and belonging in Yamatji country. The centrality of family is reflected in the myriad forms and shapes of Aboriginal spatial practices throughout and within the region.

\section{Conclusion}

Historically, Eurocentric assumptions of appropriate and civilised spatial practices resulted in policy responses which confronted the highly mobile lifestyles of Aboriginal people. In a contemporary context, the fixed nature of basic social service delivery continues to symbolise a spatial ordering where frequent mobility is marginalised. Within the current service delivery framework, discourses and interpretations of Aboriginal spatial practices serve to either reinforce or challenge a spatial ordering which privileges sedentarism. Having synthesised many of these discourses, this paper proposed an alternative framework for interpreting contemporary Aboriginal spatialities: that Aboriginal spatial practices are the product of the procurement, cultivation and contestation of security and belonging.

Several important conclusions emerge from reconceptualising Aboriginal mobility processes within this framework of security and belonging. The first is the significance of historical context in interpreting and understanding contemporary Aboriginal spatial practices. In Yamatji country today, the legacies of historical government policies continue to inform the sources from which Aboriginal people iteratively derive security and belonging. The removal of the Stolen Generations to government settlements was perhaps the most intrusive of these policies. It facilitated the creation 
and cultivation of new physical and relational spaces of security and belonging for many Yamatji people. These connections continue to inform their contemporary mobilities, expanding the distances over which people move.

A second and consequent conclusion to emerge from this reconceptualisation of Aboriginal mobility practices as processes of procuring, cultivating, and contesting security and belonging from a number of sources, is that reductionist and pejorative conceptualisations of Aboriginal spatial practices are neither instructive for the development of policy nor reflective of lived experience. As Taylor and Bell (2004a, 2004c) have proposed, contemporary Aboriginal spatial practices are the product of complex interplays between socio-cultural expression and engagement with mainstream social and economic institutions. In Yamatji country for example, a history encompassing land alienation, removal and confinement to government settlements, and marginalisation from the mainstream economy, resulted in changed spatial and socio-cultural structures. Consequently, Aboriginal populations have engaged in significant sociocultural adjustments to these colonising forces, including an appropriation of new spaces of security and belonging. Through these adjustments, Aboriginal Australians have adapted their cultural expressions and identities. Today, adjustments continue to be mediated by individual aspirations as well as cultural identification, obligations, and expressions.

A final important conclusion to emerge from this framework for understanding the complex nature of Aboriginal spatial practices in Yamatji country is the impact of life-stage and circumstances in directing the derivation of security and belonging from this interplay between mainstream institutions and socio-cultural expression. Not having mainstream employment, children of school age, accumulated material possessions, or a property to maintain (either through rental or ownership) were commonly observed by both Aboriginal and non-Aboriginal research participants as circumstances that facilitate greater mobility. However, all of these circumstances can and do change over the course of individuals' lives, and these changes alter their spatial practices. Classic migration models privilege demographic characteristics as important variables that determine individual migration trajectories (see, for example, Lee, 1966; Goldscheider, 1971; Stillwell \& Congdon, 1991). In the present analysis, even mobilities that transcend these migration models are significantly influenced by life-stage and circumstances. Changing life circumstances, individual aspirations, and contingent family relationships all unsettle the dominant discourse and simplistic categorisations of 'core' and 'transient' populations. Rather than a binary, these categorisations might be more appropriately understood as representing the two extremes of a mobility continuum along which a range of mobility processes are enacted.

Clearly, Aboriginal mobilities in Yamatji country cannot be conceived as having existed in a cultural vacuum which allows them to continue to be predicated solely on a nomadic pre-disposition to 'wander'. Rather, they have been reconfigured through an iterative process of negotiation between cultural identity and practices, and colonial and 'modernising' forces. It is through this negotiation that belonging and security are procured, contested, and cultivated in geographically unique ways. This reconceptualisation provides a framework for understanding the alternate rationalities upon which some Aboriginal mobilities are based, and for 'de-mystifying' spatial practices that do not conform to mainstream norms. It is not constricted to the notions of 'core' and 'transients', and engages in more depth with concepts of spontaneity and 
contingency that are commonly associated with the Aboriginal mobilities. Ultimately, Aboriginal mobility practices are entered into, characterised by, and shaped through a range of circumstances and considerations that can all be understood as 'rational' when placed within the framework of procuring, cultivating, and contesting security and belonging.

\section{Acknowledgements}

My thanks to the people of Yamatji country who generously gave of their time and insights to the PhD research on which this paper draws. Any errors in the translation of your contributions to this research are my sole responsibility. My thanks also to the two anonymous referees for their constructive comments. I also wish to acknowledge the Ministerial Council for Aboriginal and Torres Strait Islander Affairs, who provided the funding support to develop this paper from the $\mathrm{PhD}$ thesis.

\section{Endnotes}

1. There are considerable methodological deficiencies in the census enumeration of the Indigenous population. The census statistics presented in this discussion should therefore serve as approximations only.

2. In each of the statistics presented regarding population breakdowns by Indigenous status, there were almost as many census respondents who did not identify as either Indigenous or non-Indigenous as there were respondents who identified as Indigenous. These individuals are enumerated as part of the total population only.

3. 'Pom' is an Australian slang word for an English person.

\section{References}

Altman, J. (1987) Hunter-Gatherers Today: An Aboriginal Economy in north Australia (Canberra: Australian Institute of Aboriginal Studies).

Australian Bureau of Statistics (2007a) Census of Population and Housing Indigenous Profile, Geraldton (Indigenous) Region - WA, Cat. No. 2002.0 (Canberra: Australian Bureau of Statistics).

Australian Bureau of Statistics (2007b) Census of Population and Housing, Geraldton (L) (Urban Centre/ Locality) Basic Community Profile - WA, Cat. No. 2001.0 (Canberra: Australian Bureau of Statistics).

Australian Bureau of Statistics (2007c) Census of Population and Housing, Meekatharra (L) (Urban Centre/Locality) Basic Community Profile - WA, Cat. No. 2001.0 (Canberra: Australian Bureau of Statistics).

Barcham, M. (2004) The politics of Maori mobility, in: J. Taylor \& M. Bell (Eds) Population Mobility and Indigenous Peoples in Australasia and North America, pp. 163-183 (London: Routledge).

Beckett, J. (1965) Kinship, mobility and community among part-Aborigines in rural Australia, International Journal of Comparative Sociology, 6, pp. 7-23.

Beckett, J. (1988) Kinship, mobility and community in rural New South Wales, in: I. Keen (ed.) Being Black: Aboriginal Cultures in 'Settled Australia', pp. 117-135 (Canberra: Aboriginal Studies Press).

Bedford, R. (1981) The variety and forms of population mobility in Southeast Asia and Melanesia: The case of circulation, in: G. Jones \& H. Richter (Eds) Population Mobility and Development: Southeast Asia and the Pacific, pp. 17-49 (Canberra: The Australian National University Development Studies Centre).

Berndt, R. (1979) Traditional Aboriginal life in Western Australia: As it was and is, in: R. Berndt \& C. Berndt (Eds) Aborigines of the West: Their Past and Their Present, pp. 3-27 (Perth: University of Western Australia Press).

Birdsall, C. (1988) All one family, in: I. Keen (ed.) Being Black: Aboriginal Cultures in 'Settled Australia', pp. 137-158 (Canberra: Aboriginal Studies Press). 
Chapman, M. (1991) Pacific Island movement and socioeconomic change: Metaphors of misunderstanding, Population and Development Review, 17(2), pp. 263-292.

Chapman, M. \& Prothero, R. (1985) Circulation between 'home' and other places: Some propositions, in: M. Chapman \& R. Prothero (Eds) Circulation in Population Movement, pp. 1-13 (London: Routledge \& Kegan Paul).

Cooke, M. \& Belanger, D. (2006) Migration theories and First Nations mobility: Towards a systems perspective, Canadian Review of Sociology and Anthropology, 43(2), pp. 141-164.

Cowlishaw, G. (1999) Black modernity and bureaucratic culture, Australian Aboriginal Studies, 2, pp. $15-24$.

Douglas, W. (1981) Watjarri, in: R. Dixon \& B. Blake (Eds) Handbook of Australian Languages, pp. 197-272 (Canberra: The Australian National University Press).

Elkin, A. P. (1979) The Australian Aborigines: A Fully Revised Edition (Sydney: Angus and Robertson Publishers).

Eschbach, K. (2004) Migration and spatial distribution of American Indians in the twentieth century, in: J. Taylor \& M. Bell (Eds) Population Mobility and Indigenous Peoples in Australasia and North America, pp. 75-93 (London: Routledge).

Fink, R. (1960) The changing status and cultural identity of Western Australian Aborigines: A field study of Aborigines in the Murchison District, Western Australia 1955-1957, PhD thesis, Columbia University, 1960.

Fink, R. (1965) The contemporary situation of change among part-Aborigines in Western Australia, in: R. Berndt \& C. Berndt (Eds) Aboriginal Man in Australia: Essays in Honour of Emeritus Professor A. P. Elkin, pp. 419-434 (Sydney: Angus and Robertson).

Finlayson, J. (1991) Don’t depend on me: Autonomy and dependence in an Aboriginal community in North Queensland, PhD thesis, Australian National University, 1965.

Frideres, J., Kalbach, M. \& Kalbach, W. (2004) Government policy and the spatial distribution of Canada's Aboriginal peoples, in: J. Taylor \& M. Bell (Eds) Population Mobility and Indigenous Peoples in Australasia and North America, pp. 94-114 (London: Routledge).

Gale, F. (1967) Patterns of post-European Aboriginal migration, Proceedings of the Royal Geographical Society of Australia, South Australia Branch, 67, pp. 21-37.

Gerritsen, R. (1994) And Their Ghosts May be Heard (Perth: Fremantle Arts Centre Press).

Goldscheider, C. (1971) Population, Modernization, and Social Structure (Boston: Little, Brown and Company).

Gray, A. (2004) The formation of contemporary Aboriginal settlement patterns in Australia, in: J. Taylor \& M. Bell (Eds) Population Mobility and Indigenous Peoples in Australasia and North America, pp. 201-222 (London: Routledge).

Hamilton, A. (1987) Coming and going: Aboriginal mobility in north-west South Australia, 1970-71, Records of the South Australian Museum, 20, pp. 47-57.

House of Representatives Standing Committee on Aboriginal Affairs (1987) Return to the Country: The Aboriginal Homelands Movement in Australia (Canberra: Australian Government Publishing Service).

Kenny, C., Faries, E., Fiske, J. \& Voyageur, C. (2004) A Holistic Framework for Aboriginal Policy Research (Ottawa: Status of Women in Canada).

Lee, E. (1966) A theory of migration, Demography, 3, pp. 47-57.

Martin, D. \& Taylor, J. (1996) Ethnographic perspectives on the enumeration of Aboriginal people in remote Australia, Journal of the Australian Population Association, 13(1), pp. 17-31.

Memmott, P., Long, S. \& Thompson, L. (2006) Indigenous Mobility in Rural and Remote Australia: Final Report (Melbourne: Australian Housing and Urban Research Institute).

Milnes, P. D. (2005) From Myths to Policy: Aboriginal Legislation in Western Australia (Perth: Belco Consulting).

Moisseeff, M. (1999) An Aboriginal Village in South Australia: A Snapshot of Davenport (Canberra: Australian Institute of Aboriginal and Torres Strait Islander Studies).

Musharbash, Y. (2000) The Yuendumu community case study, in: D. Smith (ed.) Indigenous Families and the Welfare System: Two Community Based Studies, pp. 53-84, research monograph No. 17. (Canberra: Centre for Aboriginal Economic Policy Research, Australian National University).

Musharbash, Y. (2003) Walpiri sociality, PhD thesis, The Australian National University, 2003. 
Nikora, L., Guerin, B., Rua, M. \& Awekotuku, N. (2004) Moving Away from Home: Social Consequences for Tuhoe Migration to the Waikato. Available at: http://www.waikato.ac.nz/wfass/migration/docs/ guerin-tkiw-final-paper.pdf (accessed 27 October 2006).

Norris, M. J. \& Clatworthy, S. (2007) Aboriginal mobility and migration: Trends, recent patterns, and implications, in: J. White, S. Wingert, D. Beavon \& P. Maxim (2007) Aboriginal Policy Research: Moving Forward, Making a Difference, Vol. IV, pp. 207-234 (Toronto: Thompson Educational Publishing Inc.).

Palmer, K. (1982) Aboriginal religion and the ordering of social relations: The explicit and implicit meanings of religious knowledge of Aboriginal people of the north-west of Western Australia, PhD thesis, University of Western Australia, 1982.

Peterson, N. (2004) Myth of the walkabout: Movement in the Aboriginal domain in: J. Taylor \& M. Bell (Eds) Population Mobility and Indigenous Peoples in Australasia and North American, pp. 223-238 (London: Routledge).

Prout, S. (2007) Security and belonging: Reconceptualising Aboriginal spatial mobilities in Yamatji country, Western Australia, PhD thesis, Macquarie University, 2007.

Prout, S. (2008) The entangled relationship between Indigenous spatiality and government service delivery, working paper 42 (Canberra: Centre for Aboriginal Economic Policy Research).

Rose, D. (1996) Nourishing Terrains: Australian Aboriginal Views of Landscape and Wilderness (Canberra: Australian Heritage Commission).

Smith, L. R. (1980) New Black town or Black new town: The urbanization of Aborigines, in: I. Burnley, R, Pryor \& D. Rowland (Eds) Mobility and Community Change in Australia, pp. 193-208 (St Lucia: University of Queensland Press).

Smith, B. (2004) The social underpinnings of an 'outstation movement' in Cape York Peninsula, Australia, in: J. Taylor \& M. Bell (Eds) Population Mobility and Indigenous Peoples in Australasia and North America, pp. 239-261 (London: Routledge).

Smith, D. (ed.) (2000) Indigenous Families and the Welfare System: Two Community Based Studies, research monograph No. 17 (Canberra: Centre for Aboriginal Economic Policy Research, Australian National University).

Snipp, C. M. (2004) American Indians and geographic mobility: Some parameters for public policy in: J. Taylor \& M. Bell (Eds) Population Mobility and Indigenous Peoples in Australasia and North America, pp. 184-200 (London: Routledge).

Stillwell, J. \& Congdon, P. (1991) Migration modelling: Concepts and contents in: J. Stillwell \& P. Congdon (Eds) Migration Models, pp. 1-16 (London: Belhaven Press).

Taylor, J. (1996) Short-Term Indigenous Population Mobility and Service Delivery, CAEPR discussion paper No. 118 (Canberra: Centre for Aboriginal Economic Policy Research, The Australian National University).

Taylor, J. \& Bell, M. (1996) Mobility among Indigenous Australians, in: P. Newton \& M. Bell (Eds) Population Shift: Mobility and Change in Australia, pp. 392-411 (Canberra: Australian Government Publishing Service).

Taylor, J. \& Bell, M. (2004a) Conclusion: Emerging research themes, in: J. Taylor \& M. Bell (Eds) Population Mobility and Indigenous Peoples in Australasia and North America, pp. 262-267 (London: Routledge).

Taylor, J. \& Bell, M. (2004b) Continuity and change in Indigenous Australian population mobility, in: J. Taylor \& M. Bell (Eds) Population Mobility and Indigenous Peoples in Australasia and North America, pp. 13-43 (London: Routledge).

Taylor, J. \& Bell, M. (2004c) Introduction: New world demography, in: J. Taylor \& M. Bell (Eds) Population Mobility and Indigenous Peoples in Australasia and North America, pp. 1-10 (London: Routledge).

Thompson, L. (2001) Aboriginal living conditions and response paradigms, Australian Planner, 38(3-4), pp. 151-157.

Tonkinson, R. \& Tonkinson, M. (1979) Modern housing for sedentarised nomads, in: M. Heppell (Ed.) A Black Reality: Aboriginal Camps and Housing in Remote Australia, pp. 196-206 (Canberra: Australian Institute of Aboriginal Studies).

Warchivker, I., Tjapangati, T. \& Wakerman, J. (2000) The turmoil of Aboriginal enumeration: Mobility and service population analysis in a Central Australian community, Australian and New Zealand Journal of Public Health, 24(4), pp. 444-449. 
Wilson, K. \& Peters, E. J. (2005) 'You can make a place for it': Remapping urban First Nations spaces of identity, Environment and Planning D: Society and Space, 23, pp. 395-413.

Young, E. (1990) Aboriginal population mobility and service provision: A framework for analysis in: B. Meehan \& N. White (Eds) Hunter-Gatherer Demography: Past and Present, pp. 186-196 (Sydney: Oceania Monograph 39).

Young, E. \& Doohan, K. (1989) Mobility for Survival: A Process Analysis of Aboriginal Population Movement in Central Australia (Darwin: Australian National University North Australia Research Unit). 